Review Article

\title{
Are Systematic Screening for Vitamin D Deficiency and Vitamin D Supplementation Currently Feasible for Ankylosing Spondylitis Patients?
}

\author{
Mickael Essouma ${ }^{1}$ and Jean Jacques N. Noubiap ${ }^{2}$ \\ ${ }^{1}$ Department of Internal Medicine and Specialties, Faculty of Medicine and Biomedical Sciences, University of Yaoundé I, \\ Yaoundé, Cameroon \\ ${ }^{2}$ Department of Medicine, Groote Schuur Hospital and University of Cape Town, Cape Town, South Africa \\ Correspondence should be addressed to Mickael Essouma; essmic@rocketmail.com
}

Received 3 September 2016; Revised 29 October 2016; Accepted 24 November 2016; Published 2 January 2017

Academic Editor: Kamyar Kalantar-Zadeh

Copyright (C) 2017 M. Essouma and J. J. N. Noubiap. This is an open access article distributed under the Creative Commons Attribution License, which permits unrestricted use, distribution, and reproduction in any medium, provided the original work is properly cited.

\begin{abstract}
Beyond its role in calcium and phosphorus metabolism for healthy bone mineralization, there is increasing awareness for vitamin $\mathrm{D}$ contribution in modulation of immune reactions. Given that ankylosing spondylitis (AS) is a chronic inflammatory disease involving excess immune/inflammatory activity and posing great therapeutic challenges, it is conceivable to claim that vitamin $\mathrm{D}$ treatment may be a safe and effective treatment to influence or modify the primary disease and its related comorbidities. Nevertheless, consistent body of research supporting this hypothesis is still lacking. In this paper, we examine whether systematic screening and treatment for vitamin D deficiency are feasible at present. We will review the immunomodulatory role of vitamin $\mathrm{D}$ and its contribution in initiation and progression of AS, as well as how they would determine the occurrence of comorbid conditions. Our conclusion is that despite the overwhelmed interest about vitamin D treatment in AS patients, systematic screening and treatment for vitamin D deficiency of all AS patients are not feasible as yet. This stresses the need for further extensive welldesigned research to prove vitamin D efficacy in AS beyond bone protection. And if utility is proven, personalized treatment regimes, duration of treatment, and threshold values for vitamin D should be provided.
\end{abstract}

\section{Introduction}

Ankylosing spondylitis (AS) is a chronic inflammatory disease of the axial spondyloarthritis (SpA) family with prominent involvement of the spine and sacroiliac joints resulting in formation of syndesmophytes that progressively lead to bony ankylosis of the spine [1]. Other musculoskeletal features suggestive of AS include peripheral arthritis and enthesitis, whereas extra-articular features are uveitis, cardiac diseases including valve insufficiency and heart blocks, lung disease such as upper pulmonary lobe fibrosis, gastrointestinal disease which is mostly subclinical inflammatory bowel disease, retroperitoneal fibrosis, and skin disease [2]. The global prevalence of AS varies between $0.02 \%$ and $0.35 \%$ [3]. The risk and progression of AS are determined by both genetic and environmental factors. Among genetic factors, the human leukocyte antigen- (HLA-) B27 is the strongest one even though the overwhelming majority of these genes are outside the major histocompatibility (MHC) molecules along with other HLA-B alleles [4]. Environmental factors mainly include tobacco smoking [5]. The initial presentation usually occurs between the ages of 30-45 years, with a sex ratio of $3.4: 1$ (males: females) [6]. AS progression results in reduced functional capacity which is further worsened by comorbidities especially cardiovascular diseases and osteoporosis [7-9]. To limit AS progression, a large array of pharmacological treatments are currently used, nonsteroidal anti-inflammatory drugs being the mainstay and tumor necrosis factor inhibitors (TNFi) the best suitable alternative in nonresponsive patients unless there is an absolute contraindication $[10,11]$.

Vitamin D is a secosteroid hormone that contributes to calcium and phosphorus metabolism for healthy bone 
mineralization [12]. Vitamin $\mathrm{D}$ includes vitamin $\mathrm{D}_{2}$ (derived from plants) and vitamin $\mathrm{D}_{3}$ (derived from animals) as well as vitamin $\mathrm{D}$ metabolites. Most of the data from this paper focus on vitamin $\mathrm{D}_{3}$ (also known as cholecalciferol) given that vitamin $\mathrm{D}_{3}$ appears to be more effective than vitamin $\mathrm{D}_{2}$ (also known as ergocalciferol) [13]. In humans, $\sim 90 \%$ of vitamin $\mathrm{D}$ arises from endogenous synthesis by conversion of 7-dehydroxycholesterol into previtamin $\mathrm{D}$ by ultraviolet $\mathrm{B}$ radiations and then to vitamin $\mathrm{D}$ by a nonenzymatic transformation. Considering that vitamin $\mathrm{D}$ is biologically inactive, it is activated in a two-stage hydroxylation process: first, hepatic hydroxylation that results in 25-hydroxyvitamin $\mathrm{D}(25[\mathrm{OH}] \mathrm{D})$ and, second, hydroxylation of $25(\mathrm{OH}) \mathrm{D}$ in the kidneys, resulting in $1,25-(\mathrm{OH})_{2} \mathrm{D}$ which is the active form of vitamin D $[12,14]$.

Recent insights have shed light on supplemental roles of vitamin D. For instance, functional laboratory studies have shown the involvement of vitamin $\mathrm{D}$ in modulation of immune and inflammatory reactions. Along the same lines, epidemiological studies involving patients with numerous chronic inflammatory diseases including rheumatism have repeatedly suggested its implication in the occurrence and worsening of those diseases [12-15].

With respect to the relatively short half-life of $1,25(\mathrm{OH})_{2} \mathrm{D}$ ( $\sim 4$ hours), vitamin D status is best monitored by $25(\mathrm{OH}) \mathrm{D}$ which is the major circulating form of vitamin $\mathrm{D}$ with a long half-life (2-3 weeks). 25(OH)D status has been defined by various groups in the literature. Whatever the definition chosen is, levels of $25(\mathrm{OH}) \mathrm{D}$ defining vitamin $\mathrm{D}$ deficiency/insufficiency are retained on the basis of either a clinical or a biological parameter [16]. Notably, the fracture risk in elderly subjects is the main suggestive clinical parameter whereas biological criteria are elevated serum parathyroid hormone and increased bone turnover markers. In clinical practice, definitions commonly used are those provided by both the Institute of Medicine (IOM) and the Endocrine Society. According to both groups, vitamin D deficiency is defined as $25(\mathrm{OH}) \mathrm{D}$ below $20 \mathrm{ng} / \mathrm{ml}$, insufficiency as $25(\mathrm{OH}) \mathrm{D}$ of $21-29 \mathrm{ng} / \mathrm{ml}$, and sufficiency as $25(\mathrm{OH}) \mathrm{D}$ of $30-$ $100 \mathrm{ng} / \mathrm{ml}[16,17]$.

Although there is much excitement about vitamin D in the context of systemic inflammation and immune reactions and AS has been associated with low 25(OH)D in observational studies [18-20], the benefits of a putative treatment with vitamin $\mathrm{D}$ in AS patients beyond bone health are still theoretical. Notably, whether or not all AS patients should be screened and treated for vitamin D deficiency and specific treatment regimens remain unknown. Moreover, can that treatment positively influence the course of AS and related comorbid conditions beyond bone health? This review will examine in the existing literature if systematic screening and treatment for vitamin D deficiency in all AS patients are realistic.

\section{Epidemiology of Vitamin D Deficiency in "AS"}

Serum levels of $25(\mathrm{OH}) \mathrm{D}$ have been determined in AS patients and compared with healthy subjects in a number of cross-sectional studies (Table 1) [18, 19, 21-28]. The Swedish study by Klingberg et al. found no difference in serum $25(\mathrm{OH}) \mathrm{D}$ of 203 AS patients compared with 120 healthy subjects in the late winter season [21]. Nevertheless, there were significantly more users of vitamin D supplements in the AS group compared with healthy controls, what may have masked any difference. By contrast, a recent systematic review summarizing evidence from eight cross-sectional studies totalizing 555 AS patients compared with 557 healthy controls found over all studies serum mean $25(\mathrm{OH}) \mathrm{D}$ of $22.8 \pm$ $14.1 \mathrm{ng} / \mathrm{ml}$ in AS patients and $26.6 \pm 12.5 \mathrm{ng} / \mathrm{ml}$ in healthy controls. Furthermore, 25(OH)D levels were significantly higher in healthy controls $(3.8 \pm 0.8 \mathrm{ng} / \mathrm{ml}, p<0.01)$ [29].

\section{Mechanistic Link between Low Vitamin D Status and "AS"}

3.1. Immunomodulation by 1,25-Dihydroxyvitamin D. Experimental studies have shown that $1,25(\mathrm{OH})_{2} \mathrm{D}$ acts through the nuclear vitamin $\mathrm{D}$ receptor (VDR) which is found in most tissue cells including inflammatory cells, especially in macrophages, dendritic cells, and B as well as T lymphocytes [30].

1,25-Dihydroxyvitamin D can promote monocyte-tomacrophage differentiation and induce the production of immunosuppressant cytokines (e.g., prostaglandin E2) [31]. Conversely, $1,25(\mathrm{OH})_{2} \mathrm{D}$ is a potent downregulator of proinflammatory cytokines and chemokines, namely, tumor necrosis factor alpha (TNF- $\alpha$ ), interleukin-1 (IL-1), interleukin-6 (IL-6), interleukin-17 (IL-17), and interleukin-23 (IL-23) $[31,32]$. Furthermore, $1,25(\mathrm{OH})_{2} \mathrm{D}$ can impair macrophage-related antigen presentation by reducing the expression of class II MHC molecules upon their surface [32].

1,25-Dihydroxyvitamin D is also capable of inhibiting monocytes' maturation and differentiation into dendritic cells (DC). This results from downregulation of nuclear factor kappa $\mathrm{B}$ and subsequent $\mathrm{T}$ helper (Th) 1 response suppression [14]. $1,25(\mathrm{OH})_{2} \mathrm{D}$ may affect the $\mathrm{DC} / \mathrm{T}$ cell interaction via action on costimulation molecules, thus decreasing the production of proinflammatory cytokines (e.g., IL-1 and TNF- $\alpha$ ) and membrane expression of class II MHC molecules [30]. In addition, $1,25(\mathrm{OH})_{2} \mathrm{D}$ upregulates $\mathrm{CD} 4+\mathrm{CD} 25+\mathrm{T}$ regulatory cells (Treg) probably by increasing the production of Fox- $\mathrm{P}_{3}$ and interleukin-10 (IL-10) [33, 34].

Besides, 1,25( $\mathrm{OH})_{2} \mathrm{D}$ alters both $\mathrm{B}$ and $\mathrm{T}$ cell immune actions. For instance, in the case of $\mathrm{B}$ cells, acknowledged effects of $1,25(\mathrm{OH})_{2} \mathrm{D}$ are mostly limited to downregulation of their proliferation, differentiation to plasma cells, and immunoglobulin production. Concerning effector $\mathrm{T}$ cells, their immune response is suppressed both directly by inhibition of $\mathrm{T}$ cell proliferation and indirectly via $\mathrm{DC}$ inhibition and blockade of DC/T cell interaction. Suppression of T cell proliferation results in downregulation of Th1 and Th17 responses and stimulation of Th2 responses raising blood levels of antiinflammatory cytokines (e.g., IL-10). Besides Th2 upregulation, $1,25(\mathrm{OH})_{2} \mathrm{D}$ promotes Treg and $\operatorname{Tr} 1$ immunomodulating responses [30]. Altogether, $1,25(\mathrm{OH})_{2} \mathrm{D}$ may modulate immune reactions by altering immune cells production 


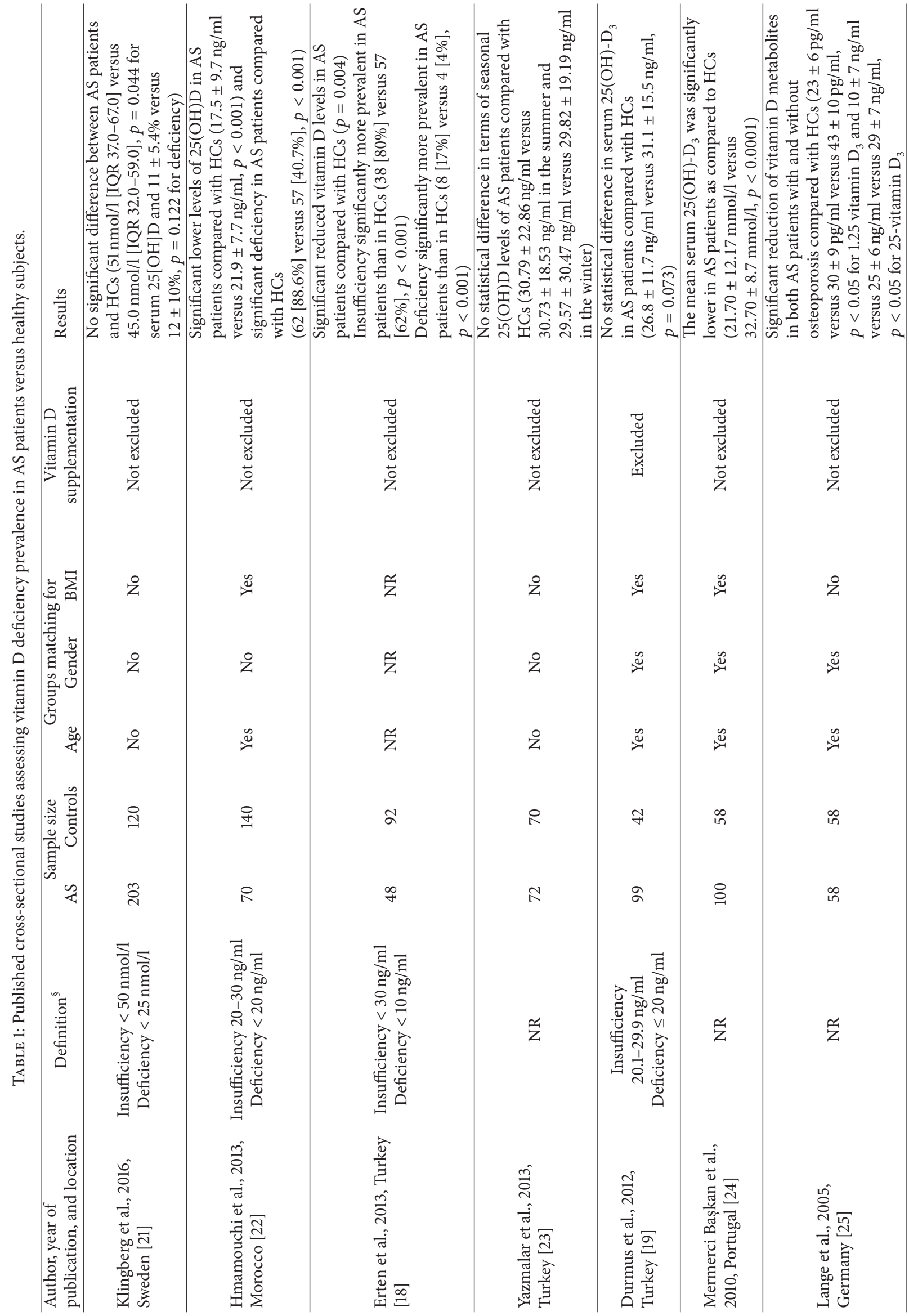




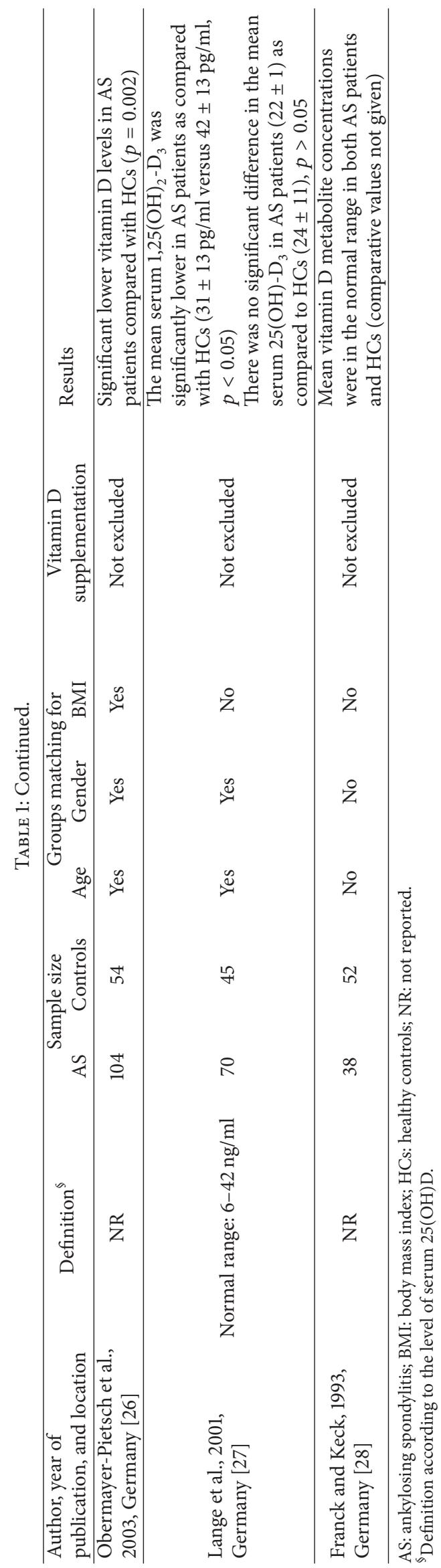




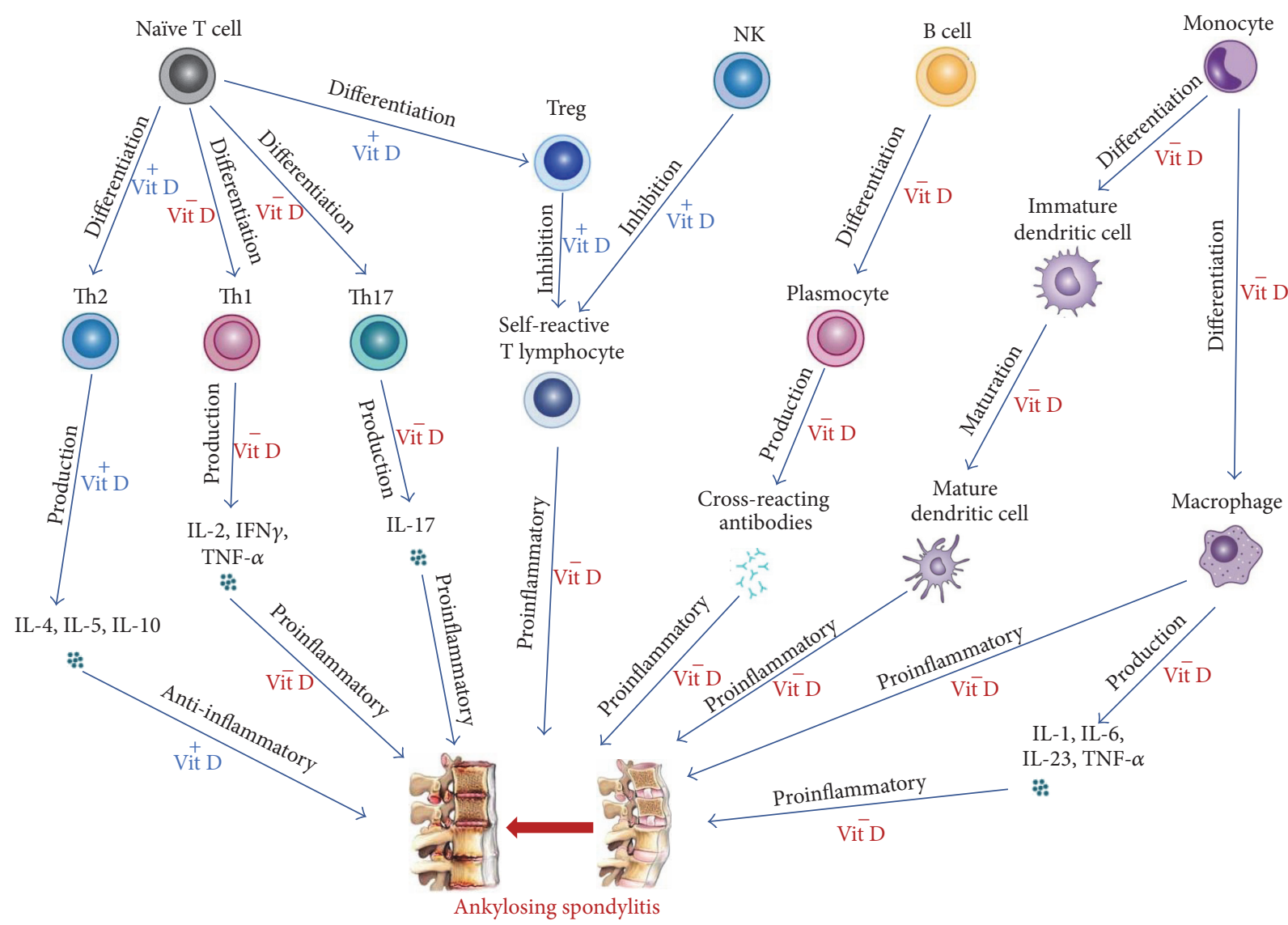

FIGURE 1: Vitamin D immunomodulatory activity influencing ankylosing spondylitis. +: stimulation by vitamin D (Vit D); -: inhibition by Vit D. Vit D can have effect on the naïve T cell, the natural killer (NK) cell, the B cell, and monocyte hence putatively inhibiting ankylosing spondylitis pathogenesis. (I) Vit D may stimulate the naïve T cell's differentiation into T helper (Th) 2 with raised production of antiinflammatory cytokines and into the T regulatory (Treg) cell, thus inhibiting the self-reactive T lymphocyte. Besides, Vit D may inhibit differentiation of the naïve T cell into Thl and Thl7 with decreased production of proinflammatory cytokines. (II) Vit D may stimulate the NK cell to inhibit the self-reactive T lymphocyte. (III) Vit D may inhibit differentiation of the B cell into plasmocyte, thus inhibiting the production of cross-reacting antibodies. (IV) Vit D may inhibit monocyte-to-dendritic cell differentiation and monocyte-to-macrophage differentiation, with consequential reduced production of proinflammatory cytokines. IL: interleukin; IFN $\gamma$ : interferon gamma; TNF- $\alpha$ : tumor necrosis factor alpha.

of proinflammatory/anti-inflammatory cytokines and by impairing their interactions (Figure 1).

3.2. Low Vitamin D Status and Risk and Severity of "AS". Vitamin D deficiency has been associated with AS [20, 29, 35]. However, there is only indirect evidence to support a putative role for $1,25(\mathrm{OH})_{2} \mathrm{D}$ in the inception of AS so far. Indeed, AS is a classic inflammatory arthritis characterized by excess production of proinflammatory cytokines, especially TNF$\alpha$, IL-6, IL-17, and IL-23. IL-6 is largely involved in the production of acute phase reactants including C-reactive protein (CRP) and initiation as well as maintenance of inflammation [4]. Besides, adaptive T cell immunity (especially Th17 and $\mathrm{CD}_{8} \mathrm{~T}$ cell responses) is crucial for initiation and progression of AS $[4,5]$. Regarding $1,25(\mathrm{OH})_{2} \mathrm{D}$ as a major contributor in immune responses that may largely alter the production of the aforementioned proinflammatory cytokines as well as antigen presentation (largely involved in T cell response) and so downregulate Th1 and Th17 immunity, one can speculate that in case of vitamin D deficiency excess immune responses might not be prevented and AS features would hence occur and evolve $[4,5,30]$.

The relationship between AS disease activity and vitamin $\mathrm{D}$ deficiency is conflicting in epidemiological studies as yet. While some studies have demonstrated a significant negative correlation between AS disease activity markers and vitamin $\mathrm{D}$ deficiency $[18,19,22,25,27]$, other studies have not found any correlation $[21,22,24,36]$. Of note, disease activity markers have extensively been assessed in all those studies, from less sensitive and specific disease activity markers including CRP and erythrocyte sedimentation rate (ESR) to more specific markers, that is, Bath AS Disease Activity Index (BASDAI) and Bath AS Functional Index (BASFI). Even though most of those studies that did not find any correlation had risk of type 2 statistic errors [20], the correlations found were weak in most of the other studies [29]. Furthermore, none of those studies completely adjusted for important confounding factors. Moreover, most studies reported results 
of $25(\mathrm{OH}) \mathrm{D}$ using mean standard deviation; meanwhile, $25(\mathrm{OH}) \mathrm{D}$ is not a normally distributed variable [20]. Consequently, results from currently available meta-analyses need to be further explored [20, 29, 37]. Taken collectively, causation is not currently proven despite some evidence for increased risk of AS in subjects with vitamin D deficiency.

3.3. Klebsiella, "AS," and 1,25-Dihydroxyvitamin D. There is overwhelming evidence from genetic, microbiological, molecular, and immunological studies supporting the crucial role of Klebsiella microbes in the initiation and perpetuation of AS through the molecular mimicry or crossreactivity pathogenic processes [38]. For instance, (i) Klebsiella microbes were isolated more frequently from the bowel of patients with active AS and their isolations were associated with clinical exacerbations of the disease; (ii) elevated levels of anti-Klebsiella antibodies were observed in the sera and jejunum fluids of AS patients when compared with matched healthy controls; (iii) molecular similarity was identified between Klebsiella nitrogenase reductase and HLA-B27 and between Klebsiella pullulanase and collagen types I, III, and IV; and (iv) in vivo cross-reactivity and cellular binding and in vitro cytotoxic activities of anti-Klebsiella antibodies were observed in patients with AS [38].

Anti-Klebsiella antibodies are therefore implicated in the inflammatory processes leading to AS through crossreaction with self-antigens in joints. As $1,25(\mathrm{OH})_{2} \mathrm{D}$ inhibits $\mathrm{B}$ cell differentiation into plasma cells and downregulates immunoglobulin production, especially IgM and IgG [39], it may reduce the proinflammatory effects of anti-Klebsiella antibodies in AS.

\section{Vitamin D Deficiency and "AS" Comorbidities}

4.1. Osteoporosis. This is an established and frequently undiagnosed and untreated complication of AS prevalent in up to $62 \%$ patients. The high risk of osteoporosis and related vertebral fractures seen in AS patients is determined by multiple factors including chronic inflammation, reduced motion in relation to pain and stiffness, and drug intake [36, 40-42]. Vitamin D deficiency is a common risk factor for osteoporosis in the general population [43]. In the AS population, the prevalence of osteoporosis seems particularly high in subgroups of patients with lower $25(\mathrm{OH}) \mathrm{D}$ compared to AS patients with normal $25(\mathrm{OH}) \mathrm{D}$ levels $[22,27]$. Nevertheless, the true relationship between vitamin $\mathrm{D}$ deficiency and osteoporosis in AS patients still eludes researchers. Arends et al. indicated low 25(OH)D to be a predictive factor for low bone mineral density (BMD) and an independent relationship was found between low 25(OH)D and bone turnover markers in a Dutch cross-sectional study involving 128 AS patients [36]. In a comparative study involving 70 male AS patients and 140 controls, Hmamouchi et al. found a significant negative correlation between serum levels of 25(OH)D and BASFI $(r=$ $0.22, p<0.001)$. BASFI was positively correlated with CRP and ESR ( $r=0.39, p<0.05$ and $r=0.36, p<0.05$, resp.). In addition, BASFI was positively correlated with lumbar spine $\mathrm{BMD}$ and femoral total BMD $(r=0.31, p<0.001$ and $r=0.32, p<0.001$, resp.). Briefly, this study suggested that vitamin $\mathrm{D}$ deficiency might indirectly lead to osteoporosis via upregulation of inflammatory activity [22]. Along the same lines, Lange et al. observed that high disease activity in AS is associated with impaired vitamin D metabolism and excess bone resorption [27]. Similarly, Obermayer-Pietsch et al. suggested that Fok1 polymorphism of the VDR gene is intimately associated with inflammatory activity, bone metabolism, and BMD [26]. Altogether, vitamin D deficiency in AS patients might indirectly and continuously enhance bone resorption via perpetration of inflammatory activity. This subsequently leads to osteoporosis.

4.2. Cardiovascular Diseases. AS patients have a 1.6-1.9-fold increased risk for cardiovascular diseases (CVD) compared with the general population [44]. Known determinants of this high cardiovascular risk are traditional CVD risk factors (hypertension, dyslipidemia, diabetes, smoking, and obesity), chronic inflammation, and disease-modifying antirheumatic drugs (DMARDs). It is noteworthy that vitamin D deficiency is a newly acknowledged risk factor for CVD in the general population. Indeed, vitamin D deficiency might be associated with endothelial dysfunction and subsequent atherosclerosis, as well as hypertension. This has been attributed to stimulation of the renin-angiotensin-aldosterone system and enhancement of proinflammatory and prothrombotic status [45]. Regarding the fact that vitamin D deficiency may be associated with the occurrence and worsening of systemic inflammation in AS and that AS is related with a high risk for CVD, it is conceivable that vitamin D deficiency could increase the risk of CVD in AS patients.

\section{Vitamin D Treatment for “AS” Patients}

5.1. Indications. To date, screening for vitamin $\mathrm{D}$ deficiency is strongly recommended only in groups of people with confirmed high risk for vitamin D deficiency in whom response to optimization of vitamin D status is expected [13, 16]. These include patients with underlying conditions (rickets, osteomalacia, osteoporosis, chronic kidney disease, hepatic failure, malabsorption syndromes, hyperparathyroidism, granuloma-forming disorders, and some lymphomas) or taking medications that interact with vitamin $\mathrm{D}$ metabolism (antiseizure medications, glucocorticoids, AIDS medications, ketoconazole, and cholestyramine), obese subjects, pregnant and lactating women, and older adults with history of falls or nontraumatic fractures as well as African-American and Hispanic adults and children [16].

While it is certain that supplements with vitamin D may be beneficial in AS patients presenting with either of the aforementioned conditions, current evidence does not support systematic supplementation with vitamin D of the whole AS population. Indeed, a strategy that would recommend systematic screening of all AS patients for vitamin D deficiency has not been proven feasible or cost-effective. In addition, whether such a strategy will be beneficial in terms of important health outcomes beyond skeletal benefits is still a matter of debate. However, numerous available epidemiological studies have suggested that sufficient 25(OH)D level 
TABLE 2: Vitamin $\mathrm{D}$ (vitamin $\mathrm{D}_{2}$ and vitamin $\mathrm{D}_{3}$ ) treatment for vitamin $\mathrm{D}$ deficiency as recommended by the Endocrine Society for the treatment of vitamin D deficiency.

\begin{tabular}{lll}
\hline Life stage group & Loading dose & Maintenance dose \\
\hline \multirow{3}{*}{$0-1$ year } & $\begin{array}{l}2000 \mathrm{IU} / \text { day or } \\
50000 \mathrm{IU} / \text { week for 6 }\end{array}$ & $400-1000 \mathrm{IU} /$ day \\
& $\begin{array}{l}\text { weeks } \\
\text { 2000 IU/day or }\end{array}$ & \\
1-18 years & $50000 \mathrm{IU} /$ week for at & $600-1000 \mathrm{IU} /$ day \\
& $\begin{array}{l}\text { least 6 weeks } \\
6000 \mathrm{IU} / \text { day or }\end{array}$ & \\
Adults & $\begin{array}{l}50000 \mathrm{IU} / \text { week for } 8 \\
\text { weeks }\end{array}$ & \\
\hline
\end{tabular}

IU: international units.

may be beneficial in reducing the risk of AS [20, 29, 37]. Even though this is not the guarantee for cost-effectiveness of AS prevention and treatment by vitamin D supplementation, we would suggest systematic screening of vitamin D deficiency for all AS patients and treatment with vitamin $\mathrm{D}$ in case of vitamin $\mathrm{D}$ insufficiency/deficiency or if the patient has either of the ascertained risk factors for vitamin $\mathrm{D}$ deficiency. Focusing on the immunomodulatory role of vitamin $\mathrm{D}$, systematic supplementation with vitamin $\mathrm{D}$ of all AS patients (irrespective of their vitamin D status) might be considered an effective add-on DMARD (alongside NSAIDs and TNFi) to reduce disease activity and comorbidities if proven effective for this indication in the future.

5.2. Dosages. Both vitamin $\mathrm{D}_{2}$ and vitamin $\mathrm{D}_{3}$ can be used for the treatment and prevention of vitamin $\mathrm{D}$ deficiency. Daily vitamin $\mathrm{D}$ requirements for the prevention of vitamin $\mathrm{D}$ deficiency vary in normal individuals by age, sex, and physiological state (lactation, pregnancy) $[13,16]$. There is no universal consensus regarding these requirements at present and clinical practice is generally based on both the Institute of Medicine (IOM) and the Endocrine Society recommendations $[17,18,46]$. Several recent studies have suggested that the recommended dietary allowances for treatment and prevention of vitamin $\mathrm{D}$ deficiency of the IOM may not be realistic, especially for patients who have underlying conditions or are taking drugs that affect vitamin $\mathrm{D}$ metabolism. Hence, the recommended treatment regimens for vitamin D deficiency summarized in Table 2 are from the Endocrine Society clinical practice guideline [16]. Vitamin D may be administered every day or once a week and therapy often begins with a loading dose for many weeks followed by a maintenance dose for many years. Notably, vitamin D treatment usually appears beneficial after up to six years of treatment without discontinuation. Of course, obese adults as well as patients receiving drugs that affect vitamin $\mathrm{D}$ metabolism require at least two to three times more vitamin $\mathrm{D}$ than doses provided here. In patients with hyperparathyroidism, vitamin D should be prescribed as needed; and in patients with granuloma-forming diseases, close monitoring of calcium during vitamin $\mathrm{D}$ therapy is necessary given the increased sensitivity for vitamin $\mathrm{D}$ and the risk of toxicity [16].
Currently, there are no specific caveats guiding either on $25(\mathrm{OH}) \mathrm{D}$ target value or on appropriate treatment regimen for vitamin $\mathrm{D}$ deficiency in the AS population. As a result, only AS patients with concurrent ascertained risk factors for vitamin $\mathrm{D}$ deficiency or those with confirmed vitamin $\mathrm{D}$ deficiency/insufficiency might be treated with vitamin $\mathrm{D}$ following the Endocrine Society guidelines in absence of thorough evidence-base supporting specific treatment modalities for AS patients. In brief, future studies should focus on vitamin $D$ treatment regimens specific to the AS population if proven necessary.

5.3. Safety. Vitamin D therapy is usually safe and its toxicity is extremely rare due to the wide therapeutic index of vitamin $\mathrm{D}$ treatment, the tightly regulated synthesis of $1,25(\mathrm{OH})_{2} \mathrm{D}$, and the characteristics of the adipose tissue which stores and slowly releases vitamin D [13, 16, 47, 48]. Although granulomatous disorders and 24-hydroxylase deficiency as well as Williams syndrome increase sensitivity to vitamin D and potential toxicity, excessive vitamin $\mathrm{D}$ intakes (especially from food supplements) raising blood levels of $25(\mathrm{OH}) \mathrm{D}$ above $150 \mathrm{ng} / \mathrm{ML}$ (as suggested by the Endocrine Society) are the main cause of vitamin D toxicity $[13,16,48-50]$. Symptoms of vitamin D toxicity mainly arise from hypercalcemia and include headaches, nervousness, arthralgia, loss of appetite, nausea, vomiting, constipation, frequent urination, excess thirst, kidney stones, and itching. Broadly, vitamin D toxicity (via hypercalcemia) is mainly responsible for systemic complications involving the skeleton, the nervous system, the digestive system, the cardiovascular system (with increased CVD risk), and kidneys (with the formation of nephrolithiasis) as well as water exchange $[48,51]$. Treatment of vitamin D toxicity consists of cessation of vitamin D intake and correct rehydration as well as administration of diuretics to increase urinary excretion of calcium $[13,16,48]$.

Despite the fact that vitamin D toxicity often appears anecdotal, it should not be ignored. Therefore, caution should be exercised when vitamin $\mathrm{D}$ is systematically administered to AS patients at large given the uncertainties regarding appropriate doses and in order to avoid toxicity.

\section{Conclusion}

According to the existing literature, it is not recommended to systematically screen and treat AS patients for vitamin $\mathrm{D}$ deficiency. Based on current guidelines, only AS patients with confirmed risk factors for vitamin D deficiency would benefit from such a strategy. While experimental studies conclude that vitamin $\mathrm{D}$ is an immunomodulatory and antiinflammatory molecule, human studies of vitamin $\mathrm{D}$ in relation to AS are still inconclusive. Is vitamin D deficiency really causative for AS or does it simply reflect enhanced systemic inflammation and poor health status in AS patients? The answer to this question is still incomplete. Any suggested additional effect of vitamin $\mathrm{D}$ beyond bone protection thus remains theoretical and we lack strong evidence that can help make specific guidelines in either the scope of vitamin $\mathrm{D}$ testing or ideal treatment modalities. Nevertheless, there remains considerable interest for vitamin $\mathrm{D}$ supplementation 
in the treatment of AS. Future longitudinal prospective studies and well-designed randomized controlled trial need to clarify whether vitamin D supplementation can be used as add-on DMARD to influence or modify AS and related comorbidities beyond its role in bone health. If proven effective, threshold values and personalized therapeutic regimes as well as treatment duration should be assessed and adopted.

\section{Abbreviations}

$\begin{array}{ll}25(\mathrm{OH}) \mathrm{D}_{3}: & \text { 25-Hydroxycholecalciferol } \\ \text { 1,25-(OH })_{2} \mathrm{D}_{3}: & \text { 1,25-Dihydroxycholecalciferol } \\ \text { AS: } & \text { Ankylosing spondylitis } \\ \text { AIDS: } & \text { Acquired immunodeficiency syndrome } \\ \text { BASDAI: } & \text { Bath Ankylosing Spondylitis Disease } \\ & \text { Activity Index } \\ \text { BASFI: } & \text { Bath Ankylosing Spondylitis Functional } \\ & \text { Index } \\ \text { BMD: } & \text { Bone mineral density } \\ \text { CRP: } & \text { C-reactive protein } \\ \text { CVD: } & \text { Cardiovascular diseases } \\ \text { DC: } & \text { Dendritic cells } \\ \text { DMARDs: } & \text { Disease-modifying antirheumatic drugs } \\ \text { ESR: } & \text { Erythrocyte sedimentation rate } \\ \text { HLA: } & \text { Human leukocyte antigen } \\ \text { IL: } & \text { Interleukin } \\ \text { IOM: } & \text { Institute of Medicine } \\ \text { MHC: } & \text { Major histocompatibility complex } \\ \text { NSAIDs: } & \text { Nonsteroidal anti-inflammatory drugs } \\ \text { Th: } & \text { T helper } \\ \text { TNF- } \alpha: & \text { Tumor necrosis factor alpha } \\ \text { TNFi: } & \text { Tumor necrosis factor inhibitors } \\ \text { VDR: } & \text { Vitamin D receptor. } \\ & \end{array}$

\section{Data Access}

Availability of Data and Material. Data sharing is not applicable to this article as no datasets were generated or analyzed during the current study.

\section{Competing Interests}

The authors declare that they have no competing interests.

\section{Authors' Contributions}

Mickael Essouma conceived the plan of the review, drafted the manuscript, and revised it. Jean Jacques N. Noubiap was involved in drafting and manuscript revision. Both authors read and approved the final manuscript.

\section{References}

[1] R. Van den Berg, X. Baraliakos, J. Braun, and D. Van der Heijde, "First update of the current evidence for the management of ankylosing spondylitis with non-pharmacological treatment and non-biologic drugs: a systematic literature review for the ASAS/EULAR management recommendations in ankylosing spondylitis," Rheumatology, vol. 51, no. 8, pp. 1388-1396, 2012.
[2] D. I. Daikh and P. P. Chen, "Advances in managing ankylosing spondylitis," F1000Prime Reports, vol. 6, article 78, 2014.

[3] C. Stolwijk, M. van Onna, A. Boonen, and A. van Tubergen, "Global prevalence of spondyloarthritis: a systematic review and meta-regression analysis," Arthritis Care \& Research, vol. 68, no. 9, pp. 1320-1331, 2016.

[4] J. D. Reveille, "Biomarkers for diagnosis, monitoring of progression, and treatment responses in ankylosing spondylitis and axial spondyloarthritis," Clinical Rheumatology, vol. 34, no. 6, pp. 1009-1018, 2015.

[5] X. Baraliakos and J. Braun, "Spondyloarthritides," Best Practice and Research: Clinical Rheumatology, vol. 25, no. 6, pp. 825-842, 2011.

[6] L. E. Dean, G. T. Jones, A. G. Macdonald, C. Downham, R. D. Sturrock, and G. J. Macfarlane, "Global prevalence of ankylosing spondylitis," Rheumatology, vol. 53, no. 4, Article ID ket387, pp. 650-657, 2014.

[7] T.-C. Shen, C.-L. Lin, C.-C. Wei et al., "The risk of asthma in patients with ankylosing spondylitis: a population-based cohort study," PLoS ONE, vol. 10, no. 2, Article ID 0116608, 2015.

[8] P. Ungprasert, N. Srivali, and W. Kittanamongkolchai, "Risk of coronary artery disease in patients with ankylosing spondylitis: a systematic review and meta-analysis," Annals of Translational Medicine, vol. 3, no. 4, article 51, 2015.

[9] N. Nigil Haroon, J. Sriganthan, N. Al Ghanim, R. D. Inman, and A. M. Cheung, "Effect of TNF-alpha inhibitor treatment on bone mineral density in patients with ankylosing spondylitis: a systematic review and meta-analysis," Seminars in Arthritis and Rheumatism, vol. 44, no. 2, pp. 155-161, 2014.

[10] J. Braun, R. Van Den Berg, X. Baraliakos et al., "2010 update of the ASAS/EULAR recommendations for the management of ankylosing spondylitis," Annals of the Rheumatic Diseases, vol. 70, no. 6, pp. 896-904, 2011.

[11] M. M. Ward, A. Deodhar, E. A. Akl et al., "American college of rheumatology/spondylitis Association of America/spondyloarthritis research and treatment network 2015 recommendations for the treatment of ankylosing spondylitis and nonradiographic axial spondyloarthritis," Arthritis Care \& Research, vol. 68, no. 2, pp. 151-166, 2016.

[12] J. A. Reynolds and I. N. Bruce, "Vitamin D treatment for connective tissue diseases: hope beyond the hype?" Rheumatology, 2016.

[13] M. G. Balvers, E. M. Brouwer-Brolsma, S. Endenburg, L. C. de Groot, F. J. Kok, and J. K. Gunnewiek, "Recommended intakes of vitamin D to optimise health, associated circulating 25hydroxyvitamin D concentrations, and dosing regimens to treat deficiency: workshop report and overview of current literature," Journal of Nutritional Science, vol. 4, article no. e23, 2015.

[14] M. Essouma and J. J. N. Noubiap, "Is air pollution a risk factor for rheumatoid arthritis?" Journal of Inflammation, vol. 12, article no. 48, 7 pages, 2015.

[15] A. Mousa, M. Misso, H. Teede, R. Scragg, and B. de Courten, "Effect of vitamin D supplementation on inflammation: protocol for a systematic review," BMJ Open, vol. 6, no. 4, Article ID e010804, 2016.

[16] M. F. Holick, N. C. Binkley, H. A. Bischoff-Ferrari et al., "Evaluation, treatment, and prevention of vitamin D deficiency: an Endocrine Society clinical practice guideline," The Journal of Clinical Endocrinology \& Metabolism, vol. 96, no. 7, pp. 19111930, 2011. 
[17] IOM (Institute of Medicine), Dietary Reference Intakes for Calcium and Vitamin D, The National Academies Press, Washington, DC, USA, 2011.

[18] S. Erten, O. Kucuksahin, A. Sahin, A. Altunoglu, M. Akyol, and C. Koca, "Decreased plasma vitamin D levels in patients with undifferentiated spondyloarthritis and ankylosing spondylitis," Internal Medicine, vol. 52, no. 3, pp. 339-344, 2013.

[19] B. Durmus, Z. Altay, O. Baysal, and Y. Ersoy, "Does vitamin D affect disease severity in patients with ankylosing spondylitis?" Chinese Medical Journal, vol. 125, no. 14, pp. 2511-2515, 2012.

[20] S. Zhao, S. J. Duffield, R. J. Moots, and N. J. Goodson, "Systematic review of association between vitamin $\mathrm{D}$ levels and susceptibility and disease activity of ankylosing spondylitis," Rheumatology, vol. 53, no. 9, pp. 1595-1603, 2014.

[21] E. Klingberg, G. Oleröd, O. Hammarsten, and H. Forsbladd'Elia, "The vitamin D status in ankylosing spondylitis in relation to intestinal inflammation, disease activity, and bone health: a cross-sectional study," Osteoporosis International, vol. 27, no. 6, pp. 2027-2033, 2016.

[22] I. Hmamouchi, F. Allali, B. E. Handaoui et al., "The relation between disease activity, vitamin $\mathrm{D}$ levels and bone mineral density in men patients with ankylosing spondylitis," Rheumatology Reports, vol. 5, no. 1, article e3, 2013.

[23] L. Yazmalar, L. Ediz, M. Alpayci, O. Hiz, M. Toprak, and I. Tekeoglu, "Seasonal disease activity and serum vitamin D levels in rheumatoid arthritis, ankylosing spondylitis and osteoarthritis," African Health Sciences, vol. 13, no. 1, pp. 47-55, 2013.

[24] B. Mermerci Başkan, Y. Pekin Doğan, F. Sivas, H. Bodur, and K. Özoran, "The relation between osteoporosis and vitamin D levels and disease activity in ankylosing spondylitis," Rheumatology International, vol. 30, no. 3, pp. 375-381, 2010

[25] U. Lange, J. Teichmann, J. Strunk, U. Müller-Ladner, and K. L. Schmidt, "Association of 1.25 vitamin D3 deficiency, disease activity and low bone mass in ankylosing spondylitis," Osteoporosis International, vol. 16, no. 12, pp. 1999-2004, 2005.

[26] B. M. Obermayer-Pietsch, U. Lange, G. Tauber et al., "Vitamin $\mathrm{D}$ receptor initiation codon polymorphism, bone density and inflammatory activity of patients with ankylosing spondylitis," Osteoporosis International, vol. 14, no. 12, pp. 995-1000, 2003.

[27] U. Lange, O. Jung, J. Teichmann, and G. Neeck, "Relationship between disease activity and serum levels of vitamin D metabolites and parathyroid hormone in ankylosing spondylitis," Osteoporosis International, vol. 12, no. 12, pp. 1031-1035, 2001.

[28] H. Franck and E. Keck, "Serum osteocalcin and vitamin D metabolites in patients with ankylosing spondylitis," Annals of the Rheumatic Diseases, vol. 52, no. 5, pp. 343-346, 1993.

[29] G. G. Pokhai, S. Bandagi, and A. Abrudescu, "Vitamin D levels in ankylosing spondylitis: does deficiency correspond to disease activity?" Revista Brasileira de Reumatologia, vol. 54, no. 4, pp. 330-334, 2014.

[30] X. Guillot, L. Semerano, N. Saidenberg-Kermanac'h, G. Falgarone, and M.-C. Boissier, "Vitamin D and inflammation," Joint Bone Spine, vol. 77, no. 6, pp. 552-557, 2010.

[31] L. Helming, J. Böse, J. Ehrchen et al., " $1 \alpha, 25$-dihydroxyvitamin D3 is a potent suppressor of interferon $\gamma$-mediated macrophage activation," Blood, vol. 106, no. 13, pp. 4351-4358, 2005.

[32] P. T. Liu, S. Stenger, H. Li et al., "Toll-like receptor triggering of a vitamin D-mediated human antimicrobial response," Science, vol. 311, no. 5768, pp. 1770-1773, 2006.

[33] M.-C. Boissier, E. Assier, J. Biton, A. Denys, G. Falgarone, and N. Bessis, "Regulatory T cells (Treg) in rheumatoid arthritis," Joint Bone Spine, vol. 76, no. 1, pp. 10-14, 2009.
[34] C. Daniel, N. A. Sartory, N. Zahn, H. H. Radeke, and J. M. Stein, "Immune modulatory treatment of trinitrobenzene sulfonic acid colitis with calcitriol is associated with a change of a $\mathrm{T}$ helper (Th) 1/Th17 to a Th2 and regulatory T cell profile," Journal of Pharmacology and Experimental Therapeutics, vol. 324, no. 1, pp. 23-33, 2008.

[35] S. V. Ramagopalan, R. Goldacre, G. Disanto, G. Giovannoni, and M. J. Goldacre, "Hospital admissions for vitamin D related conditions and subsequent immune-mediated disease: recordlinkage studies," BMC Medicine, vol. 11, no. 1, article no. 171, 2013.

[36] S. Arends, A. Spoorenberg, G. A. W. Bruyn et al., "The relation between bone mineral density, bone turnover markers, and vitamin $\mathrm{D}$ status in ankylosing spondylitis patients with active disease: a cross-sectional analysis," Osteoporosis International, vol. 22, no. 5, pp. 1431-1439, 2011.

[37] G. Cai, L. Wang, D. Fan et al., "Vitamin D in ankylosing spondylitis: review and meta-analysis," Clinica Chimica Acta, vol. 438, pp. 316-322, 2015.

[38] T. Rashid and A. Ebringer, "Ankylosing spondylitis is linked to Klebsiella-the evidence," Clinical Rheumatology, vol. 26, no. 6, pp. 858-864, 2007.

[39] E. Peelen, S. Knippenberg, A.-H. Muris et al., "Effects of vitamin $\mathrm{D}$ on the peripheral adaptive immune system: a review," Autoimmunity Reviews, vol. 10, no. 12, pp. 733-743, 2011.

[40] M. Magrey and M. A. Khan, "Osteoporosis in ankylosing spondylitis," Current Rheumatology Reports, vol. 12, no. 5, pp. 332-336, 2010.

[41] M. A. C. Van Der Weijden, T. A. M. Claushuis, T. Nazari, W. F. Lems, B. A. C. Dijkmans, and I. E. Van Der Horst-Bruinsma, "High prevalence of low bone mineral density in patients within 10 years of onset of ankylosing spondylitis: a systematic review," Clinical Rheumatology, vol. 31, no. 11, pp. 1529-1535, 2012.

[42] E. Klingberg, M. Lorentzon, D. Mellström et al., "Osteoporosis in ankylosing spondylitis-prevalence, risk factors and methods of assessment," Arthritis Research and Therapy, vol. 14, no. 3, article R108, 12 pages, 2012.

[43] K. Briot, B. Cortet, T. Thomas et al., "Actualisation 2012 des recommandations françaises du traitement médicamenteux de l'ostéoporose post-ménopausique," Revue du Rhumatisme, vol. 79, no. 3, pp. 264-274, 2012.

[44] S. Mathieu, L. Gossec, M. Dougados, and M. Soubrier, "Cardiovascular profile in ankylosing spondylitis: a systematic review and meta-analysis," Arthritis Care \& Research, vol. 63, no. 4, pp. 557-563, 2011.

[45] C. McGreevy and D. Williams, "New insights about vitamin $\mathrm{D}$ and cardiovascular disease: a narrative review," Annals of Internal Medicine, vol. 155, no. 12, pp. 820-826, 2011.

[46] A. C. Ross, J. E. Manson, S. A. Abrams et al., “The 2011 report on dietary reference intakes for calcium and vitamin $\mathrm{D}$ from the institute of medicine: what clinicians need to know," Journal of Clinical Endocrinology and Metabolism, vol. 96, no. 1, pp. 53-58, 2011.

[47] R. Vieth, "Vitamin D supplementation, 25-hydroxyvitamin D concentrations, and safety," The American Journal of Clinical Nutrition, vol. 69, no. 5, pp. 842-856, 1999.

[48] H. Ziaie, S. Razmjou, R. Jomhouri, and A. Jenabi, "Vitamin D toxicity; Stored and released from adipose tissue?" Archives of Iranian Medicine, vol. 19, no. 8, pp. 597-600, 2016.

[49] R. Vieth, "The mechanisms of vitamin D toxicity, Bone and Mineral, vol. 11, no. 3, pp. 267-272, 1990. 
[50] K. Robien, S. J. Oppeneer, J. A. Kelly, and J. M. HamiltonReeves, "Drug-vitamin D interactions: a systematic review of the literature," Nutrition in Clinical Practice, vol. 28, no. 2, pp. 194-208, 2013.

[51] F. Alshahrani and N. Aljohani, "Vitamin D: deficiency, sufficiency and toxicity," Nutrients, vol. 5, no. 9, pp. 3605-3616, 2013. 


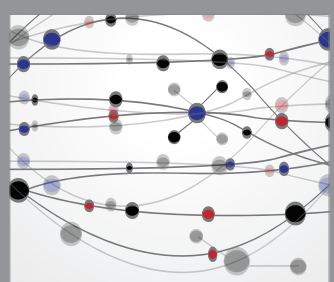

The Scientific World Journal
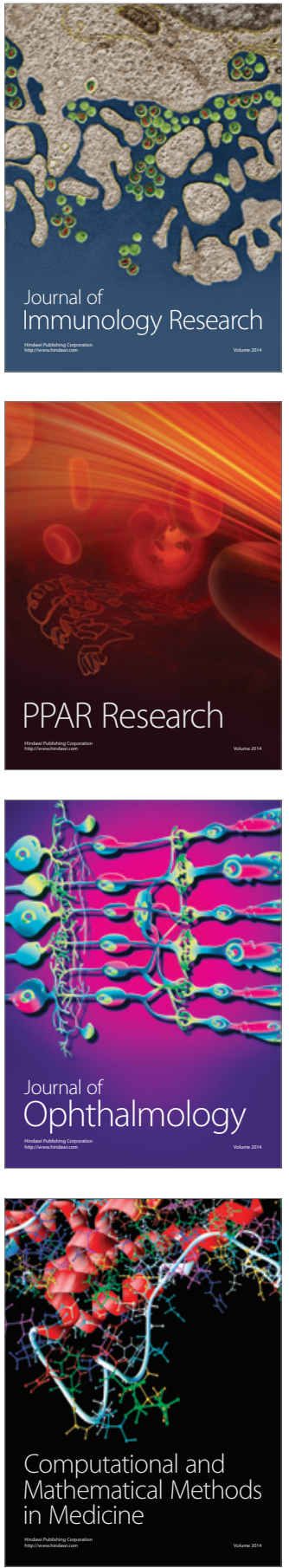

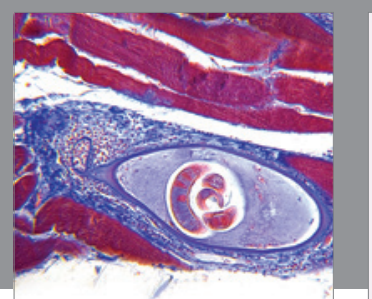

Gastroenterology Research and Practice
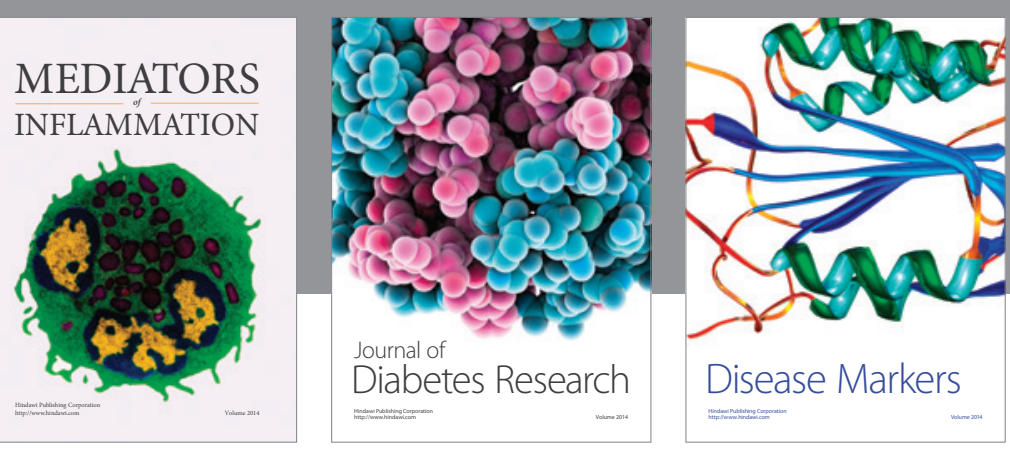

Disease Markers

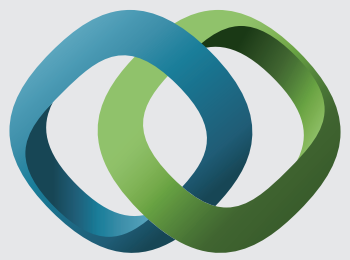

\section{Hindawi}

Submit your manuscripts at

https://www.hindawi.com
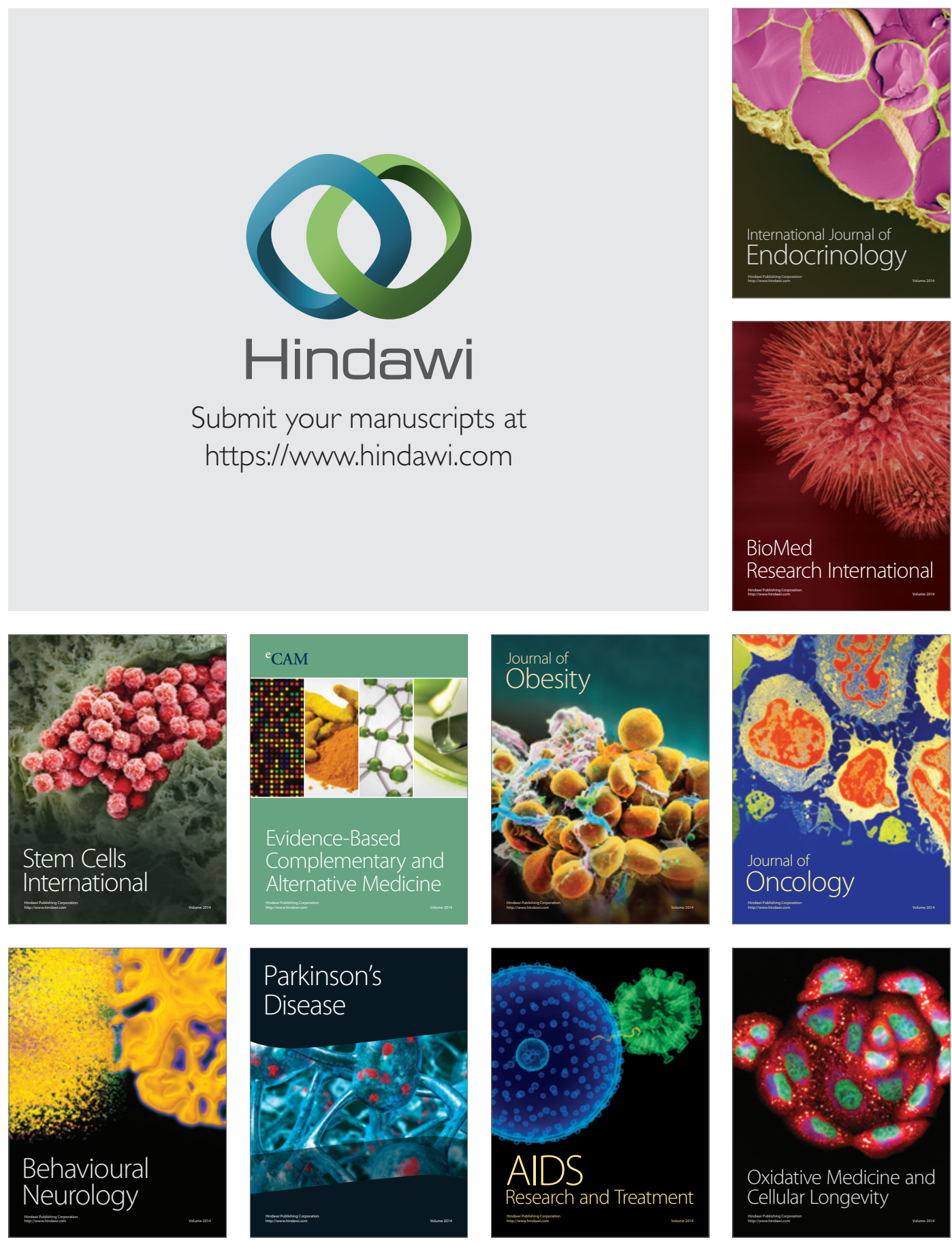